\title{
Navigated Endoport in the Purely Endoscopic Microsurgery of Intraventricular and Other Deep-Seated Brain Lesions: A Case Report
}

\author{
Roman Bosnjak, Alenka Antolin, Arne Jeglic, Tomislav Felbabic, Tomaz Velnar \\ Department of Neurosurgery, University Medical Centre Ljubljana, Ljubljana, Slovenia \\ Correspondence: tvelnar@hotmail.com; Tel.: + 3861522 3263; Fax.: + 38615222218
}

Received: 23 April 2020; Accepted: 17 July 2020

\begin{abstract}
Objective. Brain parenchyma retraction is often necessary to reach various deep brain lesions during surgery. In order to minimise the incidence of the brain retraction injury, an endoport system may be employed. We present a report of a navigated endoport system in conjunction with an purely endoscopic microsurgery that was used in a patient with a deep-seated subependymoma. Case Report. A navigated endoport with purely endoscopic microsurgery were used in a patient with a tumour located in the frontal horn of the left lateral ventricle. The endoport channel was made of a polyvinyl sheet that was cut into a $7 \mathrm{~cm}$ square, rolled into a tubular structure that was wrapped around the neuronavigational probe, and inserted in the access trajectory to the tumour. The endoport tube was then expanded with a balloon to a diameter of $7 \mathrm{~mm}$ and a surgical corridor was thus formed. During the purely endoscopic microsurgical lesionectomy, the tumour was completely removed from the frontal horn. The foramen of Monro was released and the septum pellucidum was perforated for better cerebrospinal fluid circulation. Histopathological examination confirmed the tumour as subependymoma. The recovery of the patient was unremarkable. Conclusion. The expandable endoport system supplemented with neuronavigation is a safe and efficient option for deep-seated tumour removal. The tubular shape of the retractor enables standard microsurgical techniques through minimally invasive approaches and offers an excellent visualization of the underlying lesion.
\end{abstract}

Key Words: Neuronavigation • Endoport • Neuroendoscopy • Microsurgery • Deep Brain Lesion.

\section{Introduction}

Brain retraction is often necessary in order to remove deep-seated intraaxial and intraventricular lesions. Conventional microsurgical retractor systems, such as Greenberg (Symmetry Surgical Inc., Nashville, TN, United States) and Leyla (Aesculap, Hazelwood, MO, United States) retractors, have been designed with one or two retraction spatulas that may produce significant disruptive forces to the surrounding brain tissue. The incidence of retraction injury to the cerebral cortex, white matter, and vasculature, therefore, remains high. The resulting consequences can include brain laceration with critically decreased regional blood flow leading to ischemia, permanent tissue damage, and clinically caused seizures, focal neurological defi- cits, cerebral swelling, and cognitive impairment (1-6). In addition to mechanical trauma from prolonged traction, venous infarction may also appear in a delayed fashion. From a technical point of view, retracted brain tissue often herniates back between the blades, obstructing the operative corridor and interfering with the surgical instruments and illumination. With the advent of modern neuroendoscopy, endoscopically-assisted techniques, customized instruments, and neuronavigation, the approach to deep-seated brain lesions under direct vision through a burr hole or a minimal craniotomy has become routine. Although a fully endoscopic approach is the least traumatic, it does not enable a bimanual microsurgical technique and may not lead to a complete lesion removal (7-9). 
The introduction of cylindrical retractors with microscopic and, more recently, endoscopic visualization follows the idea of a more symmetrical and less harmful distribution of pressure along the operating tube or so-called endoport (9-20). The term endoport describes a cylindrical or tubeshaped retractor system, either fixed or expandable, used as a corridor during endoscopically assisted microsurgical removal of a deep-seated brain lesion $(11,13,14,22,23)$. Neuronavigational systems and modern diagnostic imaging have greatly improved the precise targeting of these lesions and safety of the trajectory. A deep-seated brain lesion that was previously accessible only by a stereotactic biopsy can now be removed through an endoport with the help of endoscopic visualization. These deep locations in the brain that are often problematic for the surgical access, include the following: the ventricles, the basal ganglia, the pulvinar and posterior thalamus, the insular cortex, and basal cisterns. Reports of the endoport technique have already been published that describe the removal of astrocytomas, gangliogliomas, cavernous angiomas, gliomas, ependymomas, papillomas, brain abscesses, intracerebral hemorrhage, massive ventricular bleed, haematocephalus, intraventricular meningiomas, metastasis, colloid cysts, neurocytomas, and choroidal arteriovenous malformations (10-25).

We present a novel navigated endoport system in combination with an purely endoscopic technique that was used for the removal of an intraventricular tumour.

\section{Case Presentation}

\section{Patient Description}

A 75-year old gentleman presented at our neurosurgical department with occasional vertigo and insecure gait. As a result, he experienced numerous falls. Family members also noticed emotional numbness and behavioural changes. During one of the falls, he sustained a head injury. At admission, computer tomography (CT) scan revealed an expansive lesion in the left lateral ventricle with no intracranial bleeding. Magnetic resonance imaging (MRI) of the head followed a few weeks later, which confirmed a tumour located in the frontal horn of the left lateral ventricle, measuring $3.5 \mathrm{~cm}$ $\times 3 \mathrm{~cm} \times 1.5 \mathrm{~cm}$ (Figures 1 and 2).

Posteromedially, the tumour obstructed the left foramen of Monro; however, the ventricles were not enlarged. MRI also revealed a $3 \mathrm{~cm}$ thick chronic

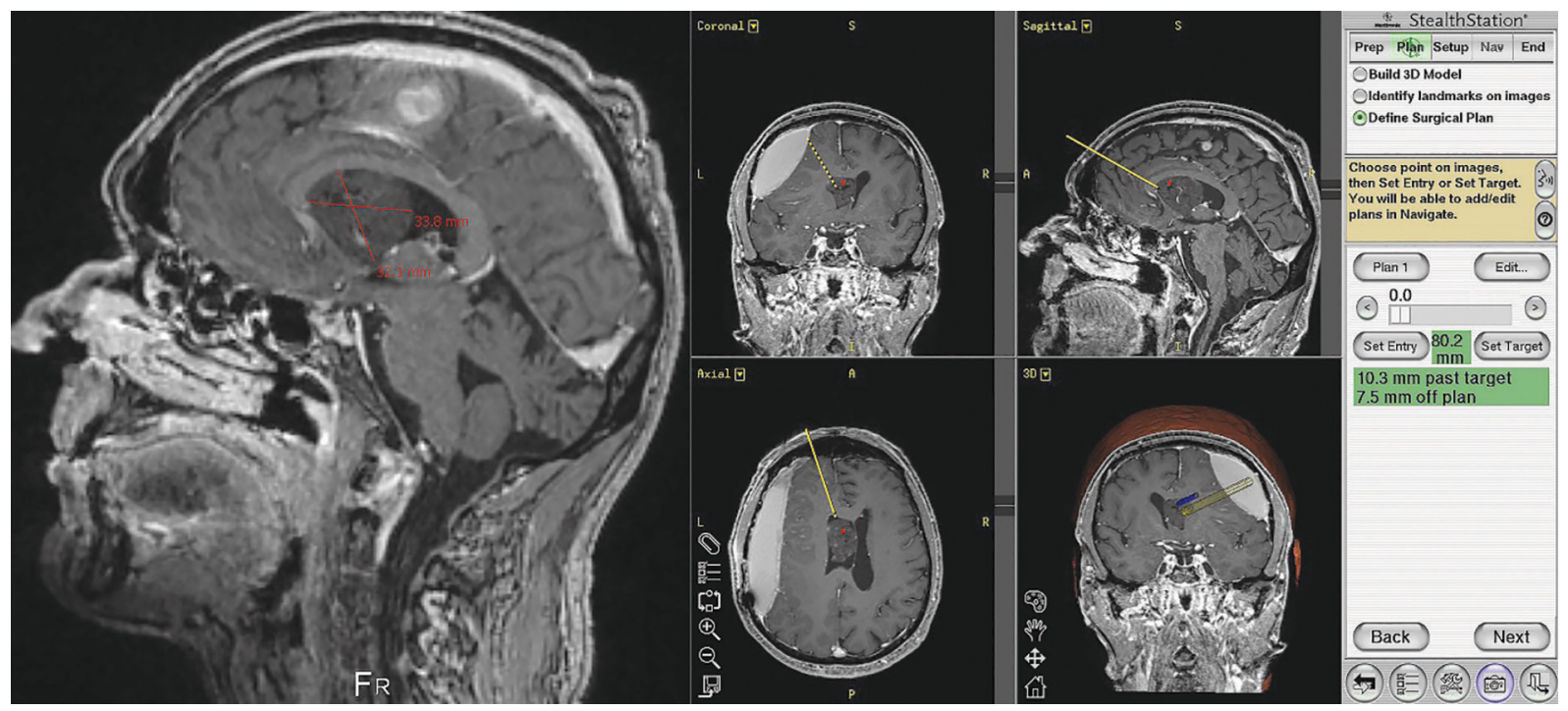

Figure 1. The surgical planning for the image-guided purely endoscopic removal of the intraventricular tumour through the endoport. A chronic subdural hematoma and a small falx meningioma are also seen. 


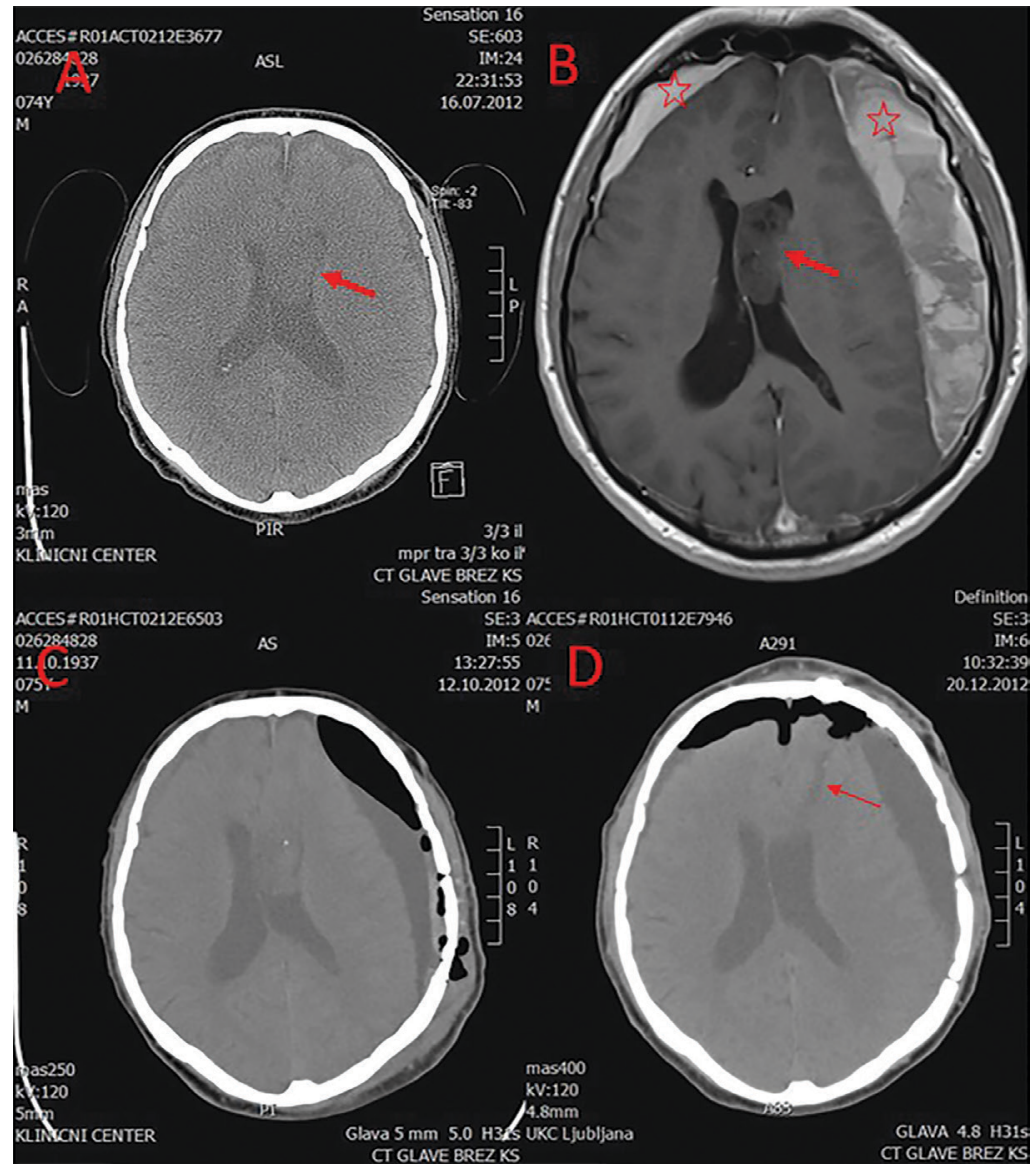

Figure 2. Initial CT revealed an accidental tumour in the left horn of the lateral ventricle (thick arrow) (A). An MRI two months later revealed chronic subdural hematomas bilaterally (star). On the left side, the haematoma is compressing the brain and causing the brain shift across the midline (B). Control CT scan after the left haematoma evacuation. On the left side, some air and fluid are still present as the brain tissue has still not expanded completely. The tumour can be seen in the left lateral ventricle (C). The last CT shows the situation 24 hours after the endoport removal of the tumour. The trace of the endoport is barely visible (thin arrow) (D).

subdural haematoma over the left hemisphere and a smaller one frontally on the right. Clinically, the patient presented with discrete right-sided hemiparesis and dysphasia. The haematoma on the left was also compressing the brain and was therefore evacuated with open surgery. One month later, the patient was operated on again in order to remove the intraventricular tumour. An endoscopically assisted minimally invasive endoport approach was planned and the tumour was removed. After the surgery, the patient became talkative and lively, and the family confirmed that his previous personality returned. The postoperative course was uneventful. The patient was discharged home a week after the operation. The histopathological examination confirmed the tumour as subependymoma.

\section{Surgical Technique}

After draping and neuronavigational setup, a $1.5 \mathrm{~cm}$ skin incision was made in the forehead wrinkle supraorbitally. The skull bone was exposed and a burr hole of $1.5 \mathrm{~cm}$ in diameter was made. The residual hematoma cavity was also explored and the thick capsule of the hygroma was fenestrated into the subarachnoidal space. Minimally invasive endoport access to the ventricles included a special expandable micro-roll retractor, which was made of a polyvinyl sheet. The sheet was cut into a $10 \mathrm{~cm} \times 7 \mathrm{~cm}$ square and rolled into a tubular shape, which was then wrapped around the neuronavigational probe (diameter of $4 \mathrm{~mm}$ ) and fixed to the probe through two stitch threads with releasable notches on the poles (Figure 3).

When inserted stereotactically via a minimal brain cortical incision and released from the probe, the roll measured about $7 \mathrm{~mm}$ in diameter. With the inflation of a 14 French Fogarty balloon attached to the catheter, the roll uncoiled to a $1 \mathrm{~cm}$ diameter, which was just enough for a spacious operative manipulation that encompassed the endoscope and surgical instruments. A $4 \mathrm{~mm}$ endoscope (Hopkins 0 degrees, Karl Storz, Tuttlingen, Germany) was introduced first, locating the lesion in the ventricle. In the meantime, the expanded endoport was held in place manually, leaning to the endoscope tube (Figure 3). The 

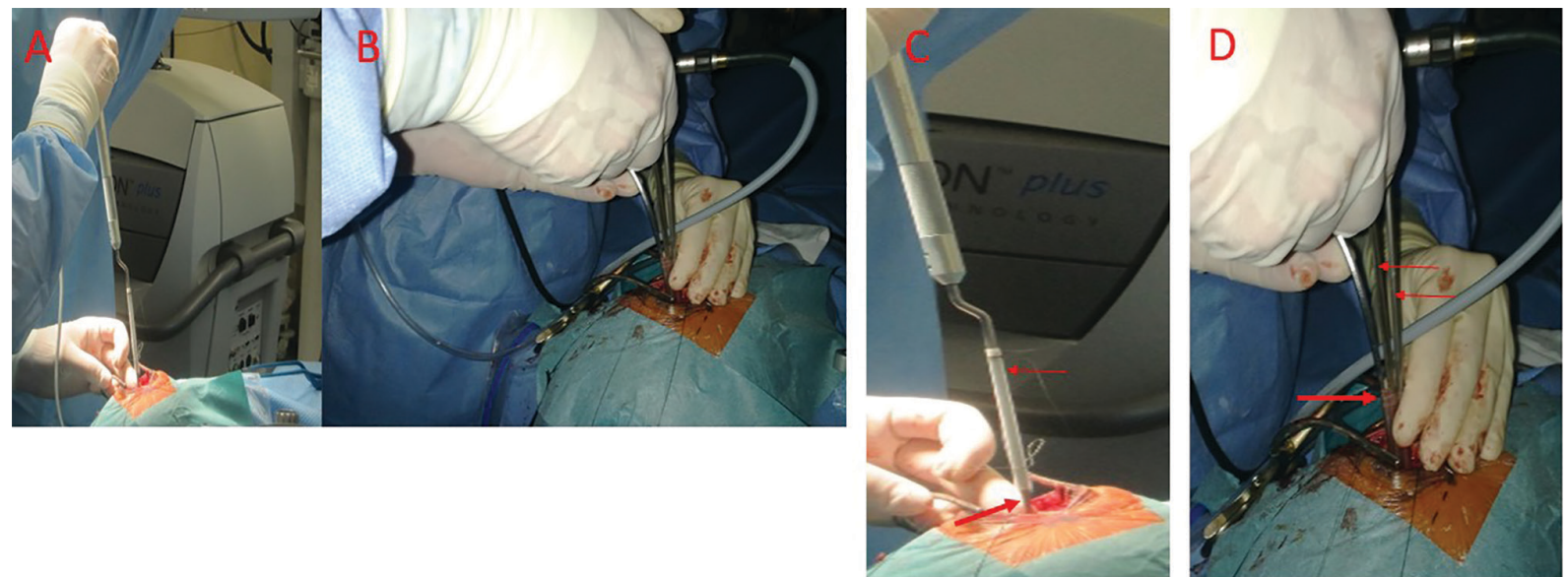

Figure 3. The intraoperative procedure of the endoport insertion under neuronavigational guidance: the neuronavigational probe with the retracted endoport just before the insertion into the brain $(A)$ and the expanded flexible working channel with surgical instruments (B). The soft vinyl sheet was rolled three times around the neuronavigational probe (diameter, $4 \mathrm{~mm}$ ) (thin arrow), secured with releasable stitches at both ends, and introduced into the brain to the target. The thick arrow denotes the neuronavigational shaft around which the soft endoport sheet was rolled. The retracted endoport can clearly be seen (C). After releasing the stitches and deployment, the tube was expanded with a Fogarty catheter to a $10 \mathrm{~mm}$ diameter and held manually to the endoscope tube. During bimanual work, the tube adopted an oval and funnel shaped configuration (thick arrow), facilitating the introduction of aspirator and grasping forceps (thin arrows) (D).

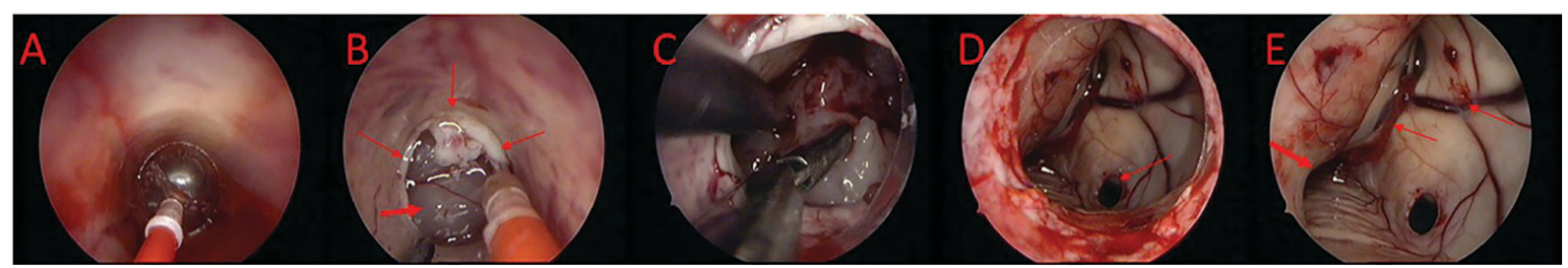

Figure 4. After insertion, the tube was expanded with a Fogarty catheter. The polyvinyl sheet, which surrounds the Fogarty catheter, is unrolling and broadens the working cannel of the expandable endoport (A). The entry into the left lateral ventricle and exposure of the tumour. The tumour tissue is grey and avascular (thick arrow) and is located just below the rim of the endoport (thin arrows). The Fogarty balloon is deflated and is removed (B). The tumour was removed by aspiration in a piecemeal fashion (C). After the tumour was removed completely, the interventricular septum was perforated in order to achieve a communication between the ventricles (arrow) (D). The foramen of Monro (thick arrow) and the thalamostriate and septal veins (thin arrows) are visible after the complete tumour removal (E).

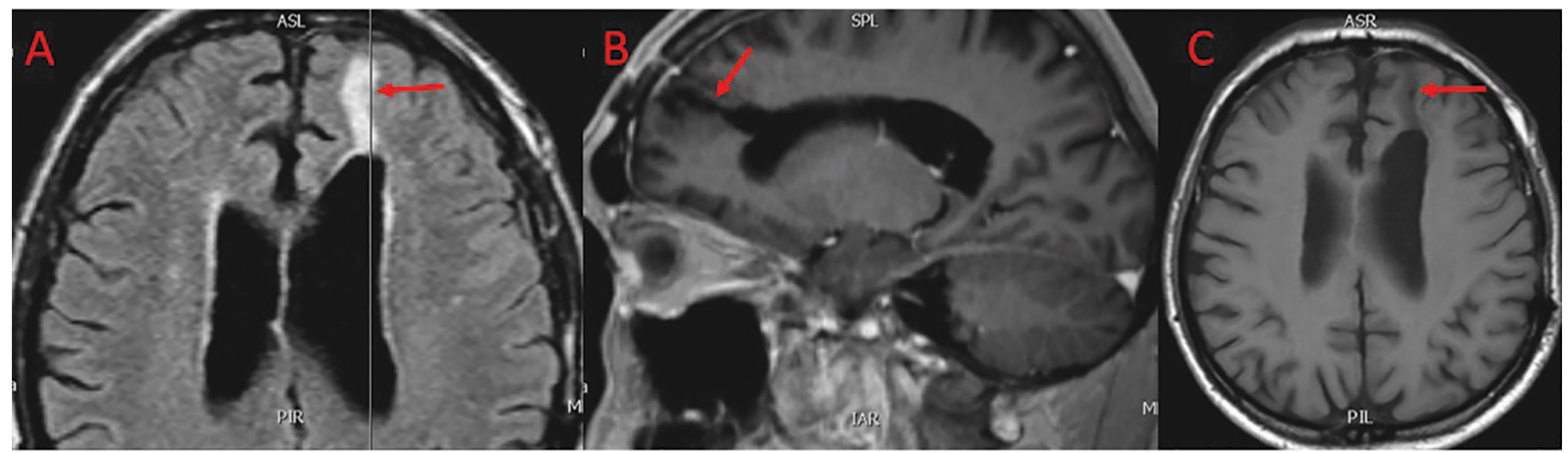

Figure 5. Control MRI three months after the operation. The tumour has been removed completely and the trace of the endoport can still be seen (arrow), morphologically confirming that very little brain trauma has been inflicted with such approach. The subdural haematoma has been resorbed completely (A, B). Follow-up MRI three years after the surgery shows a barely visible trace of the endoport access (arrow) (C). 
expanded endoport acquired an oval shape; half of the lumen was occupied with endoscope and the other half was free for introducing the surgical instruments. Two pituitary bayonet instruments were used for tumour removal through the endoport. When reaching the grey tumour mass, the endoport was first detached from the surrounding tissue and then gently aspirated until the frontal horn was completely free. The foramen of Monro was released, the third ventricle inspected, and the septum pellucidum was perforated for better cerebrospinal fluid circulation (Figure 4). Postoperative oncological treatment was not necessary; the patient is being followed-up regularly (Figure 5). The full operative video is available online at: https://www.youtube.com/watch? $v=z M n o 8 C 07 t x k$.

\section{Discussion}

With the development of the neuroendoscopic and neuronavigational technology, especially in the last decade, minimally invasive neurosurgery of deepseated lesions has progressed significantly. Surgery is becoming more patient-friendly, due to its minimal invasiveness and technological support, and also more convenient for the surgeon. Intraventricular lesions are especially difficult to reach surgically due to their deep location, demanding accessibility, and the close proximity to vital brain structures (Table 1). In the 1980s, these lesions were approached transcortically with $20 \mathrm{~mm}$ or 30 $\mathrm{mm}$ tubular cylinders that enabled binocular vision and bimanual microsurgical technique under microscopic magnification. Twenty years ago with the introduction of endoscopically-assisted microsurgery by Perneczky, the endoscope was used as an adjuvant tool for angled visualization of the whole operative field $(19,20)$. Thus, the fibre-optic based ventriculoscopy has significantly reduced the amount of cortical and white matter disruption during the surgical approach. Here, the tumours may be biopsied or removed through a working channel of the endoscope.

However, the feasibility of definitive lesion removal with fully endoscopic procedures is limited by a mono-manual technique and the restricted movements of the instruments, including operating the instrument back and forth through the tube as well as manoeuvring the endoscope shaft sidewise and up or down. Highly vascularized and firm tumours present an unacceptably high risk for complications. It is also known that prolonged or excessive brain retraction causes damage to the brain tissue and its vasculature (2, 4-6). Self-retaining retractor blades, a revolutionary assistant instrument for achieving a corridor

Table 1. The Advantages and Disadvantages of the Endoport System for Deep Brain Lesion Surgery

\begin{tabular}{|c|c|}
\hline Advantages & Limitations \\
\hline $\begin{array}{l}\text { - } \text { - Preuronavigation compatible } \\
\text { - } \text { Offers direct access to the deep lesion } \\
\text { - Less brain retraction } \\
\text { - Forces to the brain tissue are equally transmitted intermittent } \\
\text { brain retraction } \\
\text { - Flexible working channel } \\
\text { - Possibility of moving and angulating the working channel, } \\
\text { targeting it into the lesion centre and to its edge } \\
\text { - Lower possibility to damage brain vessels } \\
\text { - Lower possibility for consequent ischemia and permanent } \\
\text { tissue damage } \\
\text { - Compatible with endoscopic and endoscopically assisted } \\
\text { techniques } \\
\text { - Cheap and affordable } \\
\text { - Single use } \\
\text { - Minimal craniotomy } \\
\text { - Better aesthetic results } \\
\text { - Shorter wound healing course }\end{array}$ & $\begin{array}{l}\text { - Possibility of endoport shift } \\
\text { - Designed for endoscopically trained surgeons } \\
\text { - Requires dedicated assistance } \\
\text { - Narrow working channel } \\
\text { - Learning curve for mastering the endoport-assisted operation }\end{array}$ \\
\hline
\end{tabular}


through the brain parenchyma or for lobar retraction, was soon recognized as being hazardous, especially with long-term surgical procedures. As a result, self-retaining retractors were replaced by an intermittent retraction technique in which the retraction is performed with working instruments only. The transfissural and transsulcal approaches are further innovations for minimizing surgical trauma to the brain parenchyma $(4,5)$. On the other hand, the endoport access offers the possibility of endoscopic visualization and bimanual microscopic technique and minimizes trauma to the surrounding brain parenchyma $(21,23)$.

As the intermittent retraction with a bipolar forces and aspirator is not suitable for entering soft brain parenchyma several centimetres deep, the idea of a tubular retractor was developed and includes evenly distributed forces to the brain tissue around the retractor. In comparison to animal studies in which a significant reduction in regional cerebral blood flow with a retraction pressure of 30 $\mathrm{mmHg}$ has been studied, the retracting pressure around a cylindrical endoport up to $2 \mathrm{~cm}$ in diameter never exceeded $10 \mathrm{mmHg}(4,18)$. Postoperative T2 MRI, fluid-attenuated inversion recovery (FLAIR), and diffusion restriction/apparent diffusion coefficient (ADC) signal are the best imaging modalities to determine the extent of resection and the extent of white matter injury along the surgical trajectory $(11,13)$.

Tubular retractors can be fixed-size or expandable. Some fixed-size models are funnel-shaped for additional operative freedom. In others, the bayonet-shaped pituitary instruments are preferable. The funnel-shaped or various sizes of dilators that are inserted into the brain tissue to the target successively are further improvements in reducing brain trauma during the operation. Image-guided tubular endoport retractors have enabled the removal of many deep-seated lesions, which was also a feasible alternative to stereotactic biopsies. Additionally, surgical morbidity was decreased, and no mortality was observed $(11,13,14,19,21-23$, 25). In the recent series of Engh et al. in which resection of 32 colloid cysts and 15 intraventricular tumours was performed through an $11.5 \mathrm{~mm}$ transparent conduit, gross or near total resection was achieved in 31 (96.9\%) of the 32 colloid cysts and in $80 \%$ of intraventricular tumours, respectively. No permanent neurological morbidity occurred (11). The endoport technique has also been recently applied in posterior fossa surgery via the lateral transcerebellar route (26-28).

Neurosurgical planning is of vital importance for a successful surgical outcome. The planned trajectories during neuronavigational employment may be affected by brain shifts and dislocations, especially after cerebrospinal fluid aspiration or leak, or after larger resections. If trajectories are not planned carefully, the targeted lesions may be missed, especially when they are small and in a deep location. In our patient, planning for the tumour surgery was done after the operation of the chronic subdural haematoma on the left, which can clearly be seen from the preoperative MRI plans. The subdural haematoma was evacuated first as this was the acute cause for patient's neurological symptoms. In the second phase, MRI-based planning was performed to determine the trajectory for the tumour removal. The surgical trajectory was not planned through the haematoma and the associated brain tissue, but according to the tumour location itself. In this case, the brain shift was not important for the navigation and did not affect the trajectory, since the trajectory started in the entry point on the skull bone (which is immobile) and terminated in the tumour, the location of which did not change. We did not experience any problems during the operation and the navigation was precise, targeting the endoport directly into the tumour.

Outside of rare commercially available models, most tubular retractors can be assembled with equipment and material already available at many institutions $(13,15,19,22)$. Our polyvinyl roll used for endoport was a low-cost modification of an expendable transparent polyvinyl tube introduced by Jho in 2002 (17). The tube was rolled from a very soft $10 \mathrm{~cm} \times 7 \mathrm{~cm}$ polyvinyl sheet and was then uncoiled with a Fogarty catheter from the initial $4 \mathrm{~mm}$ to the final $10 \mathrm{~mm}$ diameter. During the bimanual work, the tube adopted a more 
oval and funnel shaped configuration that facilitated the introduction of curved teardrop aspirators and grasping forceps. Because the polyvinyl roll had several turns, it never unrolled completely during the surgery. Its elastic structure enabled rolling with each retrieval of the instruments and unrolling with each introduction of instrumentsits diameter never exceeded $1 \mathrm{~cm}$. This dynamic effect further minimized pressure to the surrounding brain parenchyma.

According to reports in the literature, the first endoscopic removal of a third ventricular tumour through a polyvinyl sheath rolled into a cigarette shape and inserted with image-guided stereotactic assistance into the lateral ventricle and foramen Monro was reported in 2002. This polyvinyl tube was expanded with a balloon dilatation technique (17). A rigid $7 \mathrm{~mm}$ polypropylene tube was used to remove a neurocytoma with aspiration, a unipolar coagulating aspirator, and visualization with a $2.7 \mathrm{~mm}$ 0-degree optics (10). A longitudinally cut silicone tube has been reported as a low-cost endoport (29). Selected tumours, however, can be removed with a fully endoscopic approach to the third ventricle using a diode laser for vaporization of the tumour (20). To avoid thermal injury to the brain stem, several authors prefer mechanical removal of the tumour, which is possible with a microsurgical bimanual technique. The endoscopic single-port or dual-port approaches offer this possibility. A side-cutting instrument, combining variable aspiration and cutting function from a lateral aperture, has been used successfully in keyhole craniotomies, endoscopic endonasal approaches, and more recently in transcranial port surgery (30). The tubular retractor system used in spinal surgery (METRx; Medtronic, Minneapolis, $\mathrm{MN}$ ) has been used microscopically to remove deep-seated parenchymal lesion $(12,13,31)$. This system includes a progressive dilatation of the corridor using a set of dilating tubes.

\section{Conclusion}

The expandable endoport surgery minimizes skin incision, craniotomy size, and retractor-induced trauma to brain tissue. It has the potential for improving treatment outcome and lowering complications in endoscopic neurosurgery of intraventricular and deep-seated brain lesions with the use of standard microsurgical techniques under endoscopic visualization.

\section{What Is Already Known on this Topic:}

In an operation of deep-seated intraaxial and intraventricular lesions, brain retraction is necessary and may produce disruptive forces to the brain tissue. The consequence can be brain laceration that leads to ischemia and the tissue damage. With the introduction of modern neuroendoscopy, endoscopically assisted techniques, customized instruments, and neuronavigation, these lesions can be removed less invasively and in a more patient-friendly manner.

\section{What this Case Adds:}

Deep brain lesions may be safely and effectively managed by the endoport technique. Expandable endoport surgery minimizes the skin incision, craniotomy size, and retractor-induced trauma to the brain. It has the potential to improve surgical outcome and lowering complications associated with endoscopic neurosurgery of intraventricular and deepseated brain lesions.

Authors' Contributions: Conception and design: RB and AA; Acquisition, analysis and interpretation of data: $\mathrm{AJ}$ and TF; Drafting the article: RB, AA and TV; Revising it critically for important intellectual content: RB, AJ, and TV; Approved final version of the manuscript: $\mathrm{RB}, \mathrm{AA}, \mathrm{AJ}, \mathrm{TF}$ and $\mathrm{TV}$.

Conflict of Interest: The authors declare that they have no conflict of interest.

\section{References}

1. Greenberg IM. Self-retaining retractor and handrest system for neurosurgery. Neurosurgery. 1981;8(2):205-8.

2. Donaghy RM, Numoto M, Wallman LJ, Flanagan ME. Pressure measurement beneath retractors for protection of delicate tissues. Am J Surg. 1972;123(4):429-31.

3. Hansen KV, Brix L, Pedersen CF, Haase JP, Larsen OV. Modelling of interaction between a spatula and a human brain. Med Image Anal. 2004;8(1):23-33.

4. Rosenorn J, Diemer N. The risk of cerebral damage during graded brain retractor pressure in the rat. J Neurosurg. 1985;63(4):608-11.

5. Rosenorn J, Diemer NH. Reduction of regional cerebral blood flow during brain retraction pressure in the rat. J Neurosurg. 1982;56(6):826-9.

6. Zhong J, Dujovny M, Perlin AR, Perez-Arjona E, Park HK, Diaz FG. Brain retraction injury. Neurol Res. 2003;25(8):831-8. 
7. Kelly PJ. Future perspectives in stereotactic neurosurgery: stereotactic microsurgical removal of deep brain tumors. J Neurosurg Sci. 1989;33(1):149-54.

8. Kelly PJ, Goerss SJ, Kall BA. The stereotaxic retractor in computer-assisted stereotaxic microsurgery. Technical note. J Neurosurg. 1988;69(2):301-6.

9. Kelly PJ, Kall BA, Goerss SJ. Computer- interactive stereotactic resection of deep-seated and centrally located intraaxial brain lesions. Appl Neurophysiol. 1987;50(16):107-13.

10. Cheng CH, Liu CL, Chen CC, Lin SZ, Cho DY. Singleport endoscopic removal of intraventricular central neurocytoma. J Clin Neurosci. 2010;17(11):1417-20.

11. Engh JA, Lunsford LD, Amin DV, Ochalski PG, Fernandez-Miranda J, Prevedello DM, et al. Stereotactically guided endoscopic port surgery for intraventricular tumor and colloid cyst resection. Neurosurgery. 2010;67(3):198205.

12. Fahim DK, Relyea K, Nayar VV, Fox BD, Whitehead WE, Curry DJ, et al. Transtubular microendoscopic approach for resection of a choroidal arteriovenous malformation. J Neurosurg Pediatr. 2009;3(2):101-4.

13. Greenfield JP, Cobb WS, Tsouris AJ, Schwartz TH. Stereotactic minimally invasive tubular retractor system for deep brain lesions. Neurosurgery. 2008;63(4):334-40.

14. Harris AE, Hadjipanayis CG, Lunsford LD, Lunsford AK, Kassam AB. Microsurgical removal of intraventricular lesions using endoscopic visualization and stereotactic guidance. Neurosurgery. 2005;56(1):125-32.

15. Herrera SR, Shin JH, Chan M, Kouloumberis P, Goellner E, Slavin KV. Use of transparent plastic tubular retractor in surgery for deep brain lesions: a case series. Surg Technol Int. 2010;19:47-50.

16. Ichinose T, Goto T, Morisako H, Takami T, Ohata K. Microroll retractor for surgical resection of brainstem cavernomas. World Neurosurg. 2010;73(5):520-2.

17. Jho HD, Alfieri A. Endoscopic removal of third ventricular tumors: a technical note. Minim Invasive Neurosurg. 2002;45(2):114-9.

18. Ogura K, Tachibana E, Aoshima C, Sumitomo M. New microsurgical technique for intraparenchymal lesions of the brain: transcylinder approach. Acta Neurochir (Wien). 2006;148(7):779-85.

19. Raza SM, Recinos PF, Avendano J, Adams H, Jallo GI, Quinones-Hinojosa A. Minimally invasive trans-portal resection of deep intracranial lesions. Minim Invasive Neurosurg. 2011;54(1):5-11.

20. Romano A, Chibbaro S, Makiese O, Marsella M, Mainini $\mathrm{P}$, Benericetti E. Endoscopic removal of a central neurocytoma from the posterior third ventricle. J Clin Neurosci. 2009;16(2):312-6.

21. Kassam AB, Engh JA, Mintz AH, Prevedello DM. Completely endoscopic resection of intraparenchymal brain tumors. J Neurosurg. 2009;110(1):116-23.

22. Recinos PF, Raza SM, Jallo GI, Recinos VR. Use of a minimally invasive tubular retraction system for deepseated tumors in pediatric patients. J Neurosurg Pediatr. 2011;7(5):516-21.

23. Jo KI, Chung SB, Jo KW, Kong DS, Seol HJ, Shin HJ. Microsurgical resection of deep-seated lesions using transparent tubular retractor: pediatric case series. Childs Nerv Syst. 2011;27(11):1989-94.

24. Moshel YA, Link MJ, Kelly PJ. Stereotactic volumetric resection of thalamic pilocytic astrocytomas. Neurosurgery. 2007;61(1):66-75.

25. Jo KW, Shin HJ, Nam DH, Lee JI, Park K, Kim JH, et al. Efficacy of endoport-guided endoscopic resection for deepseated brain lesions. Neurosurg Rev. 2011;34(4):457-63.

26. Rhoton AL Jr. The lateral and third ventricles. Neurosurgery. 2002;51(4):207-71.

27. Shapiro S, Rodgers R, Shah M, Fulkerson D, Campbell RL. Interhemispheric transcallosal subchoroidal fornixsparing craniotomy for total resection of colloid cysts of the third ventricle. J Neurosurg. 2009;110(1):112-5.

28. Ochalski PG, Fernandez-Miranda JC, Prevedello DM, Pollack IF, Engh JA. Endoscopic port surgery for resection of lesions of the cerebellar peduncles: technical note. Neurosurgery. 2011;68(5):1444-51.

29. Yadav YR, Yadav S, Sherekar S, Parihar V. A new minimally invasive tubular brain retractor system for surgery of deep intracerebral hematoma. Neurol India. 2011;59(1):74-7.

30. McLaughlin N, Ditzel Filho LF, Prevedello DM, Kelly DF, Carrau RL, Kassam AB. Side-cutting aspiration device for endoscopic and microscopic tumor removal. J Neurol Surg B Skull Base. 2012;73(1):11-20.

31. Almenawer SA, Crevier L, Murty N, Kassam A, Reddy K. Minimal access to deep intracranial lesions using a serial dilatation technique: Case- series and review of brain tubular retractor systems. Neurosurg Rev. 2013;36(2):32130 . 